BMJ Open Sport \& Exercise Medicine

\title{
Damaging nature of decelerations: Do we adequately prepare players?
}

\author{
Damian James Harper, ${ }^{1,2}$ John Kiely ${ }^{2}$
}

To cite: Harper DJ, Kiely J. Damaging nature of decelerations: Do we adequately prepare players? BMJ Open Sport \& Exercise Medicine 2018;4:e000379. doi:10.1136/ bmjsem-2018-000379

Accepted 17 July 2018

\section{Check for updates}

(C) Author(s) (or their employer(s)) 2018. Re-use permitted under CC BY-NC. No commercial re-use. See rights and permissions. Published by BMJ.

${ }^{1}$ School of Sport, York St John University, York, UK ${ }^{2}$ Institute of Coaching and Performance, School of Sport and Wellbeing, University of Central Lancashire, Preston, UK

Correspondence to Dr Damian James Harper; d.harper@yorksj.ac.uk

\section{AN EVOLVING UNDERSTANDING OF MATCH DEMANDS}

Frequent and intense accelerations and decelerations are crucial elements of match play. ${ }^{1-4}$ Both accelerations and decelerations expose players to high levels of mechanical stress, are recognised as key contributors to overall biomechanical load, ${ }^{5}$ and may exert a significant impact on performance potential (eg, ability to sustain high force output and attenuation). Consequently, accelerations and decelerations are recognised as important variables to monitor. ${ }^{6}$

The use of newly available motion tracking technologies has permitted a more comprehensive characterisation of the external loads associated with whole-body biomechanical loading. ${ }^{6}$ This information can, in turn, be used to inform and refine training prescription and management processes. Although evidence suggests that the mechanical stressors imposed during accelerating and decelerating activities are fundamentally different, ${ }^{6}$ current recommendations for optimal load monitoring seemingly treat the consequences of these loads-in terms of potential tissue damage and subsequent adaptations-as equivalent. ${ }^{5}$ Evolving an optimally perceptive load monitoring paradigm, however, demands that if different loading activities impose differentially and disproportionately damaging consequences, we should identify the external loads posing the most significant threats to both performance and injury risk, and weigh them accordingly. ${ }^{7}$

\section{THE DISTINCT DEMANDS OF ACCELERATION AND DECELERATION}

Recent match analysis data obtained from global positioning systems (GPS) and triaxial accelerometers highlight two core distinctions between accelerations and decelerations. First, when examining the comparative frequencies of accelerations and decelerations, it is clear that more accelerations occur within low to moderate intensity ranges than similarly intense decelerations. ${ }^{4}$ Beyond high-intensity thresholds, however, decelerations evidently occur more frequently than equivalently intense accelerations. In soccer, for example, high-intensity decelerations are up to 2.9 times more frequent than high-intensity accelerations. ${ }^{3}$ Presumably, this discrepancy is a feature of competitive match play, such that accelerations to higher running velocities may frequently occur gradually, without crossing a defined high-intensity threshold, whereas, in contrast, a larger proportion of decelerations are suddenly imposed, thereby enforcing rapid velocity reductions within constrained timeframes and spaces.

Second, when compared with more 'concentrically-dependent' accelerations, the sudden braking activity implicit in severe decelerations demands intense eccentric and quasi-isometric contractions. These contraction modes are capable of generating higher muscular tensions than concentric actions. Nevertheless, presumably as a consequence of the elevated mechanical loads experienced during decelerations, the fatigue and cumulative tissue microtrauma imposed following deceleration activities are greater than that following similarly intense accelerations. ${ }^{1-3}$ Consequently, the load per metre experienced during decelerations is up to $65 \%$ greater (effect size $=2$, very large) than any other match play activities, and approximately $37 \%$ more than when accelerating. ${ }^{4}$

\section{DECELERATION-SPECIFIC LOAD: COULD THIS BE A CRITICAL MEDIATOR?}

A recent British Journal of Sports Medicine editorial called for exploration of the mediators driving load-related injuries, and more training-specific data informing injury resilience protocols. ${ }^{8}$ In responding to this call, we propose that the mechanical stressors, implicit in deceleration activities, are critical mediators serving as potent drivers of both neuromuscular fatigue and tissue damage. Increasing fatigue and accumulative tissue microtrauma, subsequently, both act to further diminish the coordinative capacities underpinning an 


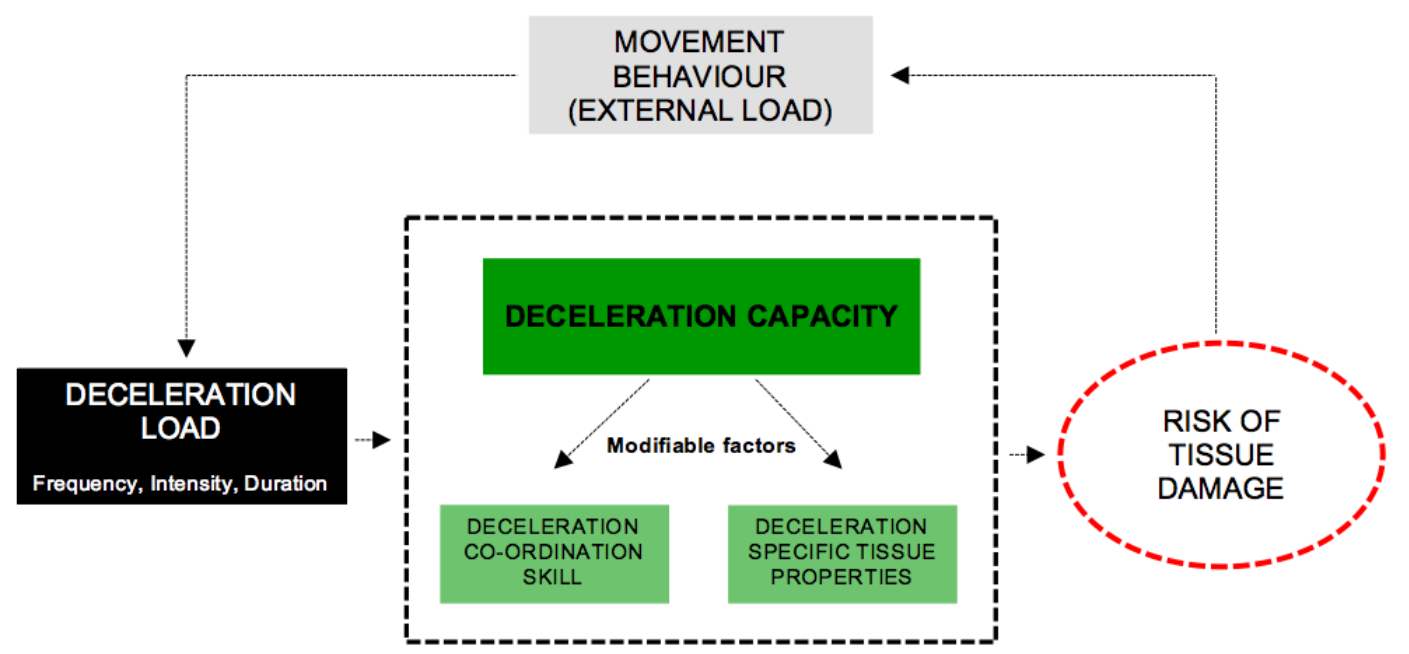

Figure 1 Deceleration capacity represented as a critical mediator moderating the performer's risk of tissue damage.

ability to skilfully dissipate braking loads. Consequently, increasing volume or intensity of deceleration activity contributes to a vicious cycle of ever-increasing fatigue, diminishing coordinative proficiency and subsequent risk of accumulating tissue damage (figure 1).

\section{INCREASING PLAYER RESILIENCE TO DECELERATIVE LOAD: SHOULD THIS BE A PRIORITY?}

Specifically in relation to the enhancement of deceleration abilities, few validated training recommendations currently exist. In prompting future discussion, we suggest priority should be given to the following:

1. Measurement and management of decelerative loads:

Deceleration volumes and intensities, for example, are sensitive indicators of tissue loading, ${ }^{6}$ the extent of tissue damage ${ }^{23}$ and subsequent injury risk. ${ }^{1}$ As such, careful consideration should be given to the selection of quantifiable variables and methodological procedures through which deceleration loads can be measured and managed. For example, more informative insights may be obtained by quantifying the deceleration impulse per foot strike (mass $\times$ deceleration) using newly available metrics, such as force load. ${ }^{6}$

2. Monitoring progressive exposure to decelerations: The basic training principle of gradual progressive overload suggests that optimal match play preparation should include incrementally progressive exposure to deceleration loadings. ${ }^{1}$ Such accurate training prescription logically demands regular and sensitive monitoring of deceleration-induced load, and subsequently imposed decrements. A decline in eccentric force, measured during a simple countermovement jump using force plates, for example, has been proposed as an insightful indicator of deceleration-induced fatigue. ${ }^{3}$

3. Selection of loading strategies enhancing deceleration capacity: Clearly, empirically informed training strategies focused on increasing player resilience to the negative consequences of repeated decelerations are urgently required. We tentatively suggest that resilience to deceleration activity can be augmented via (1) increasing the load-bearing capacities of lower limb tissues, and (2) nurturing the coordinative skill of deceleration by exposing players to challenges enhancing more sensitive and accurate calibration of the muscular co-contraction patterns, and limb positioning strategies, essential to proficient deceleration activity (figure 1).

In closing, training-specific research, and training practice in general, has historically focused primarily on enhancing acceleration and high-velocity running capacities. While such efforts are undoubtedly important, the future evolution of match play preparation philosophy also requires that we develop training techniques focused on enhancing deceleration-handling capacities, in tandem with aligned monitoring strategies enabling us to better discern and quantify the specific mechanical stressors driving deceleration-imposed deficits. Finally, these insights may hold special relevance for those tasked with the management, delivery and monitoring of training interventions designed to enhance injury resilience and reduce injury risk.

Twitter Damian James Harper @DHMov and John Kiely @simplysportssci.

Acknowledgements The authors acknowledge Dale Forsdyke for reviewing and providing feedback on a draft of the manuscript.

Contributors DJH and JK both contributed equally to the planning and development of this editorial. DJH was responsible for writing the editorial, with JK making revisions.

Funding The authors have not declared a specific grant for this research from any funding agency in the public, commercial or not-for-profit sectors.

Competing interests None declared.

Patient consent Not required.

Provenance and peer review Not commissioned; externally peer reviewed.

Open access This is an open access article distributed in accordance with the Creative Commons Attribution Non Commercial (CC BY-NC 4.0) license, which permits others to distribute, remix, adapt, build upon this work non-commercially, and license their derivative works on different terms, provided the original work is properly cited, appropriate credit is given, any changes made indicated, and the use is non-commercial. See: http://creativecommons.org/licenses/by-nc/4.0/ 


\section{REFERENCES}

1. Jaspers A, Kuyvenhoven JP, Staes F, et al. Examination of the external and internal load indicators' association with overuse injuries in professional soccer players. J Sci Med Sport 2018;21:579-85.

2. Young WB, Hepner J, Robbins DW. Movement demands in Australian rules football as indicators of muscle damage. J Strength Cond Res 2012;26:492-6.

3. de Hoyo M, Cohen DD, Sañudo B, et al. Influence of football match time-motion parameters on recovery time course of muscle damage and jump ability. J Sports Sci 2016;34:1363-70.

4. Dalen T, Ingebrigtsen J, Ettema G, et al. Player load, acceleration, and deceleration during forty-five competitive matches of elite soccer. $J$ Strength Cond Res 2016;30:351-9.
5. Vanrenterghem J, Nedergaard NJ, Robinson MA, et al. Training load monitoring in team sports: a novel framework separating physiological and biomechanical load-adaptation pathways. Sports Med 2017;47:2135-42.

6. Buchheit M, Simpson BM. Player-tracking technology: half-full or half-empty glass? Int J Sports Physiol Perform 2017;12(Suppl 2):S2 35-S2-41.

7. Gabbett TJ, Whiteley R. Two training-load paradoxes: can we work harder and smarter. can physical preparation and medical be teammates? Int J Sports Physiol Perform 2017;12:50-4.

8. Windt J, Zumbo BD, Sporer B, et al. Why do workload spikes cause injuries, and which athletes are at higher risk? Mediators and moderators in workload-injury investigations. Br J Sports Med 2017;51:993-4. 